\title{
SCARLESS HYSTERECTOMY- EXTENDED INDICATIONS AND ITS SAFETY IN NON-DESCENT UTERI
}

\author{
Benudhar Pande1, Babita Ramani², Santhosh Kumar Dora3 , Lalmohan Nayak, Sudhanshu Sekhar Nath ${ }^{5}$
}

${ }^{1}$ Assistant Professor, Department of Obstetrics and Gynaecology, VIMSAR, Burla.

${ }^{2}$ Consultant, Department of Obstetrics and Gynaecology, Sanjivani Hospital, Jharsuguda.

${ }^{3}$ Assistant Professor, Department of Obstetrics and Gynaecology, VIMSAR, Burla.

${ }^{4}$ Professor, Department of Obstetrics and Gynaecology, VIMSAR, Burla.

5Senior Resident, Department of Obstetrics and Gynaecology, VIMSAR, Burla.

\section{BACKGROUND}

ABSTRACT

Hysterectomy is the most common surgery done in the gynaecological world. With the introduction of vaginal route for hysterectomy for non-descent uteri, gynaecologist have found a way of hysterectomy without any scar on abdomen, hence it is also called scarless hysterectomy.

Aim- Assessment of characteristics of patient and the uterus as well as recognising the most common and uncommon indications for hysterectomy via vaginal route in non-descent uteri.

\section{MATERIALS AND METHODS}

Total number of vaginal hysterectomies for non-prolapsed uteri for benign causes, done at tertiary hospital, in a period of 21 months from September 2012 to May 2014 were prospectively studied for their indication, accessibility and safety for the procedure.

\section{RESULTS}

Amongst 127 women who underwent vaginal hysterectomy for non-descent uteri, 46 (36.2\%) were operated for dysfunctional uterine bleeding followed by adenomyosis in 32 (25.2\%) followed by fibroid in 30 patients (23.6\%) and endometriosis in 3 (2.3\%) cases. 5 (3.9\%) cases were having uterine size larger than 16 weeks. 13 (10.2\%) of cases had previous caesarean section and 64 $(50.4 \%)$ had bilateral tubal ligation. $3(2.3 \%)$ women were nulliparous. Oophorectomy was done as an associated surgery in 14 $(11.02 \%)$ cases. Vaginal route was changed to laparotomy in $1(0.7 \%)$ case for intraoperative haemorrhage and pelvic adhesion. Rectovaginal fistula occurred in $1(0.7 \%)$ case. No deaths were recorded within the study period. Mean duration of surgery was 45 min. \pm 23 min. Mean hospital stay was 72 hours \pm 24 hours.

\section{CONCLUSION}

Non-descent scarless vaginal hysterectomy is safe with wide range of indications avoiding the need for open method or assisted laparoscopic method. More and more skill development programs in non-descent vaginal hysterectomy are required to increase the indications of non-descent vaginal hysterectomy in gynaecological world.

\section{KEYWORDS}

Vaginal Hysterectomy, Non-descent Uteri, Scarless Hysterectomy, Rectovaginal Fistula.

HOW TO CITE THIS ARTICLE: Pande B, Ramani B, Dora SK, et al. Scarless hysterectomy- Extended indications and its safety in non-descent uteri. J. Evolution Med. Dent. Sci. 2017;6 (42):3317-3319, DOI: 10.14260/Jemds/2017/718

\section{BACKGROUND}

Hysterectomy is the most common surgery done in gynaecological world. ${ }^{1}$ Hysterectomy can be done by four ways at present scenario viz. abdominal hysterectomy, vaginal hysterectomy, laparoscopic and robotic hysterectomy. Laparoscopic hysterectomy or abdominal hysterectomy is frequently compared with vaginal hysterectomy for benign causes in non-descent uteri in many studies.1,2,3 These studies failed to show the benefit of other route over vaginal hysterectomy. Vaginal hysterectomy is a natural hole surgery and it has hardly any intra-abdominal handling. There are so many uncommon indications like big

Financial or Other, Competing Interest: None.

Submission 20-04-2017, Peer Review 14-05-2017,

Acceptance 20-05-2017, Published 25-05-2017.

Corresponding Author:

Dr. Babita Ramani,

Sanjivani Hospital, Siria Bagicha,

Ekatali, Jharsuguda-768202,

Odisha, India.

E-mail: babitarmani@gmail.com

DOI: $10.14260 /$ jemds $/ 2017 / 718$

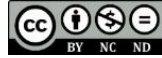

size uterus, nulliparous uterus, previous caesarean section or any pelvic surgery and multiple fibroid in non-descent uteri with benign causes. ${ }^{4}$ Among them, usual limitations in vaginal hysterectomy with non-descent uteri are bigger sizes, but now even with bigger sizes, hysterectomy can be facilitated by bisection, myomectomy, wedge debulking, intramyometrial coring, morcellation and newer technique like technique of electrocautery and radiofrequency technology of sutureless surgery. ${ }^{5}$ An increase in caesarean section rate will also become a limiting factor for the vaginal approach of hysterectomy in future. If the limiting factors increase day by day then the art of vaginal hysterectomy, which in real sense is a scarless surgery, will be lost someday. Gynaecologists, however, are more reluctant to do the nondescent vaginal hysterectomy. The limitations for this route is lack of training programs and promotions regarding nondescent vaginal hysterectomy unlike laparoscopic hysterectomy. Nowadays the world is focusing more on laparoscopic training program and emerging robotic surgery training program. So we have to fight with the limiting factors and increasing the scope for the vaginal hysterectomy. Vaginal hysterectomy ensures fastest recovery and less 
intraoperative as well as postoperative complications. ${ }^{2}$ Subsequent randomised studies have shown that laparoscopic hysterectomy and its derivatives are associated with advantage that are similar to those of non-descent vaginal hysterectomy.6,7 Non-descent vaginal hysterectomy gives the benefits of minimally invasive technique like shorter duration, less handling, less morbidity, earlier recovery, best cosmetic and low cost benefit. ${ }^{\circ}$ Vaginal hysterectomy has been made easy, accessible and visible even in larger non-prolapsed uteri by newer (electrocautery) technique. ${ }^{9}$ Mazdisnian $\mathrm{F}$ et al in 1995 concluded that with increasing concern over the containment of health care cost, there is a need for expanding the indications for performing vaginal hysterectomy. ${ }^{10}$

\section{MATERIALS AND METHODS}

This was a descriptive study conducted in a tertiary care teaching hospital, for the period of 21 months from September 2012 to May 2014. It included all the cases which had undergone vaginal hysterectomy in non-prolapsed uteri for benign disorders. The cases needing hysterectomy were admitted, examined, investigated, reviewed and information was recorded in proforma. The primary indication and patient's characteristics were given emphasis. Patients with uterus size till 20 weeks (Mainly those who were having contraindication for long general anaesthesia like hypertension or increasing age and high risk for abdominal route like diabetes mellitus) with benign diseases and nondescent uteri were included. Patients with complex adnexal mass, malignancy or restricted mobility (Like endometriosis) were excluded. Proper consent for surgery was taken. Injection adrenalin in a concentration of 1:100000 was injected into the vesicovaginal fascia to decrease the blood loss. The uterus was freed from the supports from the pelvic walls by conventional method of vaginal hysterectomy. Different techniques like bisection, myomectomy and intramyometrial coring were employed to remove bigger size uteri. Vault was fixed with uterosacral ligaments at its angle on both sides to reduce the incidence of vault prolapse. Vault was closed conventionally. Difficulties and complications, met during surgery and in post-op period, were noted.

\section{RESULTS}

The total number of women underwent for vaginal hysterectomy in non-descent uteri for benign causes was 127 over the study period. Mean age of women of undergoing non-descent hysterectomy was 44.8 years \pm 4.9 years and range of 34 to 64 years. Mean parity was $4 \pm 1$. It was observed that $64(50.3 \%)$ patients had bilateral tubectomy and $13(10.2 \%)$ patients had previous caesarean section. The most common indication for the procedure (table-1) was dysfunctional uterine bleeding $(36.2 \%)$ followed by adenomyosis $(25.2 \%)$, fibroid $(23.6 \%)$ and endometriosis 3 $(2.3 \%)$ cases. Most common uterine size was ten to twelve weeks size (which underwent hysterectomy). There were 14 to 16 weeks uteri which were operated vaginally in 13 $(10.2 \%)$ of cases and $5(3.9 \%)$ women had uterus size more than 16 weeks (table-2). Among all women, 2.3\% women were nulliparous (table-3). Mean operating time was 45 minutes \pm 23 minutes. Mean blood loss during procedure was $60 \mathrm{~mL} \pm 26 \mathrm{~mL}$. Average hospital stay was 72 hours \pm 24 hours. In $6(4.72 \%)$ cases the hospital stay was more than 4 days. Intra-operative bleeding occurred in one case $(0.7 \%)$. Blood transfusion had been given to six $(4.7 \%)$ women. No intra-operative injury had occurred to adjacent organs but one $(0.7 \%)$ rectovaginal fistula had manifested on fourth post-operative day. Most common post-operative complication (Table-4) was fever (3.1\%) followed by severe pain in lower abdomen (1.5\%).

\begin{tabular}{|c|c|c|c|}
\hline Sl. No. & Indications & No. & \% \\
\hline 1 & Adenomyosis & 32 & $25.20 \%$ \\
\hline 2 & DUB & 46 & $36.22 \%$ \\
\hline 3 & Fibroid & 30 & $23.62 \%$ \\
\hline 4 & $\begin{array}{c}\text { Post-menopausal } \\
\text { Bleeding }\end{array}$ & 5 & $3.94 \%$ \\
\hline 5 & Endometrial Polyp & 11 & $8.66 \%$ \\
\hline 6 & Endometriosis & 3 & $2.36 \%$ \\
\hline \multicolumn{3}{|c|}{ Table 1. Indications for Vaginal Hysterectomy } \\
\hline
\end{tabular}

\#DUB=Dysfunctional Uterine bleeding.

\begin{tabular}{|c|c|c|c|}
\hline Sl. No. & Uterine Size (In Weeks) & No. & \% \\
\hline 1 & NS-8 & 16 & $12.60 \%$ \\
\hline 2 & $10-12$ & 51 & $40.16 \%$ \\
\hline 3 & $14-16$ & 13 & $10.24 \%$ \\
\hline 4 & $>16$ & 5 & $3.94 \%$ \\
\hline \multicolumn{3}{|c|}{ Table 2. Uterine Characteristics } \\
\hline
\end{tabular}

*NS=normal size.

\begin{tabular}{|c|c|c|c|}
\hline Sl. No. & Parity & No. & \% \\
\hline 1 & Nullipara & 3 & $2.36 \%$ \\
\hline 2 & 1 to 2 & 30 & $23.62 \%$ \\
\hline 3 & 3 to 4 & 58 & $45.67 \%$ \\
\hline 4 & 5 to 8 & 36 & $28.35 \%$ \\
\hline \multicolumn{4}{|c|}{ Table 3. Parity } \\
\hline
\end{tabular}

\begin{tabular}{|c|c|c|c|}
\hline Sl. No. & Procedure & No. & \% \\
\hline 1 & Oophorectomy & 14 & $11.02 \%$ \\
\hline 2 & Laparotomy & 1 & $0.79 \%$ \\
\hline 3 & Bisection & 49 & $38.58 \%$ \\
\hline 4 & Myomectomy & 23 & $18.11 \%$ \\
\hline 5 & Wedge debulking & 18 & $14.17 \%$ \\
\hline \multicolumn{3}{|c|}{ Table 4. Assisted Intraoperative Procedure } \\
\hline
\end{tabular}

\begin{tabular}{|c|c|c|c|}
\hline Sl. No. & Morbidity & No. & \% \\
\hline 1 & Haemorrhage & 1 & $0.79 \%$ \\
\hline 2 & Severe pain & 2 & $1.57 \%$ \\
\hline 3 & Rectovaginal Fistula & 1 & $1.57 \%$ \\
\hline 4 & Abdominal Bloating & 1 & $0.79 \%$ \\
\hline 5 & Fever (urinary tract infection) & 4 & $3.15 \%$ \\
\hline \multicolumn{3}{|c|}{ Table 5. Post-operative Morbidity } \\
\hline
\end{tabular}

\section{DISCUSSION}

In a multicentric study, Chaitra $\mathrm{R}$ et al has shown that for properly selected cases vaginal hysterectomy is the preferred route in the hands of experienced surgeons. ${ }^{11}$ With the introduction of newer techniques, ${ }^{9}$ for removal of larger uterus during virginal hysterectomy, we are able to perform hysterectomy through vaginal route in some unfavourable situations like nulliparous women, uterus size more than twelve weeks and endometriosis, although the time taken in these cases was more than the usual situation. The removal of bigger size uterus was the most challenging part during the whole procedure, which was tackled by bisection, wedge debulking, intramyometrial coring and myomectomy. Three 
patients are nulliparous where the uterus size was eight to twelve weeks. In a study done by Kumari $\mathrm{S}$ et $\mathrm{al}, 12$ dysfunctional uterine bleeding (44\%) was the most common indication followed by Pelvic inflammatory disease (26\%) whereas in our study it was dysfunctional uterine bleeding (36.2\%) followed by adenomyosis (25.2\%) and fibroid $(23.6 \%)$. The rarest indication for vaginal hysterectomy was endometriosis in our study, which was found incidentally during opening of pouch of Douglas with difficulty. These are the cases which were previously diagnosed as adenomyosis. Oophorectomy was also performed in fourteen cases $(11.02 \%)$ with the help of right angle clamp in our study whereas in a multicentric study it has been only $4.5 \% .^{11}$ Intra-operative haemorrhage in one case was due to posterior adhesion to pouch of Douglas. Total postoperative complications were at $7.8 \%$, whereas in one study ${ }^{11}$ it was reported that total $9.6 \%$ complications had occurred with urinary tract infection in $2.7 \%$, wound infection in $5.4 \%$ and vaginal bleeding in $1.3 \%$ cases which were comparable. The rectovaginal fistula was not due to injury to the rectum by scissors or scalpel, but due to suturing the rectum to vault by taking a deep bite during suturing the vault. This case was managed by involving a surgeon and performing colostomy. No other organ injuries were noted in study population. Due to high range of antibiotics, the febrile morbidity was reduced in our study. Febrile morbidity was seen in very few cases in our study and that was due to urinary tract infection. Pain in lower abdomen in post-operative period might be due to less pain threshold in some women. The main advantage of vaginal hysterectomy is requirement of spinal anaesthesia and almost nil intra-abdominal handling. This causes faster recovery in terms of oral intake and mobilisation of the patients. The most important thing is that there is no fear of secondary wound infection in high risk patients like diabetes mellitus. In the present study, the characteristics of women also included the patients who were previously a candidate for abdominal or laparoscopic hysterectomy. In our study, we have seen that the technique of vaginal surgery is helpful in cases where long general anaesthesia for laparoscopy is contraindicated.

The vaginal hysterectomy in non-descent uteri should be taken as minimally invasive surgery as the postoperative period was almost uneventful in our study population. Nowadays, new advancement in the technologies like electrocautery, radiofrequency, etc. have minimised the trauma and time as well as providing a safer and easier access to the uterus. ${ }^{5}$ Gynaecologists can also use uterine volume calculation by ultrasound pre-operatively for assessing the feasibility of the procedure done vaginally. ${ }^{13} \mathrm{We}$ should have the technique of vaginal hysterectomy in nondescent uteri in our mind as the first line of thought for feasible to hardly feasible conditions where hysterectomy is required to reduce the hospital stay as well as post-operative morbidity and enhance the post-operative recovery. This will expand the indications of scarless hysterectomy. It is still having all those indications which are not thought to be, after invention of the laparoscopy.

\section{CONCLUSION}

We believe that scarless hysterectomy has a wide range of indications with very few limitations but it depends on proper case selection and surgeon's experience and skill to newer techniques, which minimises complications and morbidity and also converts an abdominal procedure into vaginal one with its advantages as well as minimising the procedures like laparoscopic hysterectomy. We also believe that more and more skill development programs in nondescent vaginal hysterectomy is required to increase the indications of non-descent vaginal hysterectomy in gynaecological world and also to preserve the beautiful art of non-descent vaginal hysterectomy.

\section{REFERENCES}

[1] Wilcox LS, Koonin LM, Pokras R, et al. Hysterectomy in United State, 1988-1990. Obstet Gynecol 1994;83(4):549-55.

[2] Dicker RC, Greenspan JR, Strauss LT, et al. Complications of abdominal and vaginal hysterectomy among women of reproductive age in United States. The collaborative review of sterilization. Am J Obstet Gynecol 1982;144(7):841-8.

[3] Kovac SR. Guidelines to determine the route of hysterectomy. Obstet Gynecol 1995;85(1):18-23.

[4] Davies A, Vizza E, Bournas N, et al. How to increase the proportion of hysterectomy performed vaginally. Am J Obstet Gynecol 1998;179(4):1008-12.

[5] Unger JB. Vaginal hysterectomy for woman with moderately enlarged uterus weighing 200-700 grams. Am J Obstet Gynecol 1999;180(6 Pt 1):1337-44.

[6] Nezhat F, Nezhat C, Gordon S, et al. Laparoscopic versus abdominal hysterectomy. J Reprod Med 1992;37(3):247-50.

[7] Raju KS, Auld BJ. A randomized prospective study of laparoscopic vaginal hysterectomy versus abdominal hysterectomy each with bilateral salpingo oophorectomy. $\mathrm{Br} \mathrm{J}$ Obstet Gynaecol 1994;101(12):1068-71.

[8] Jogson N, Barlow D, Leathaby A, et al. Surgical approach to hysterectomy for benign gynecological diseases. Cochrane Database Syst Rev 2005;(1):CD003677.

[9] Purohit RK, Pattnaik AK. Vaginal hysterectomy by electrosurgery (an extraperitoneal approach). B J Obstet Gynecol India 2001;51(5):162-4.

[10] Mazdisnian F, Kurzel RB, Coe S, et al. Vaginal hysterectomy by uterine morcellation: an efficient, non morbid procedure. Obstet Gynecol 1995;86(1):604.

[11] Ramachandra C, Ramlingappa, Deepa, et al. Vaginal hysterectomy for non-descent uterus - a prospective multicentric study. Women's Health \& Gynecol 2016;2(5):34.

[12] Kumari S, Mitra N, Shrivastava S. Nondescent vaginal hysterectomy, a changing practice in Indian scenario for scar less surgery. Int J Med Res Rev 2016;4(1):4751.

[13] Das S, Sheth S. Uterine volume: an aid to determine the route and technique of hysterectomy. J Obstet Gynecol Ind 2004;54(1):68-72. 